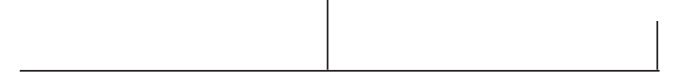

Rev. Latinoam. Psicopat. Fund., São Paulo, 16(4), 683-695, dez. 2013

\title{
Possibilidades e desafios na inclusão escolar
}

Bruna Kibrit

Apresenta-se o caso de um acompanhamento terapêutico feito junto a uma aluna com síndrome de Down, a trajetória cumprida junto a ela e junto à escola. Discute-se a possibilidade de construir um projeto singular e o lugar em que a educação se encontra para o surgimento de um sujeito desejante.

Palavras-chave: Inclusão escolar, psicanálise, acompanhamento terapêutico e educação 


\section{Uma trajetória junto a Marina: um acompanhamento terapêutico (ou uma assistente de classe?)}

No início de 2011 fui contratada por uma escola particular para ser assistente de classe do terceiro ano do ensino médio, com a principal função de fazer a inclusão de uma aluna com sindrome de Down. Logo que fui apresentada à adolescente, Marina, percebi que ela era uma menina tímida, que falava muito pouco e dificilmente olhava o rosto de quem conversava com ela.

No início do acompanhamento eu não sabia muito como agir. Percebia que havia uma cobrança pedagógica feita pela escola, à qual eu não sabia se daria conta de corresponder. Considerava que, pelo menos no início, o mais importante era conhecer Marina, e não cobrá-la em relação às tarefas escolares.

Ficava dividida entre duas demandas que refletiam visões diferentes de inclusão. A da escola, que focava mais em conteúdos dados em aula, e a minha, que reconhecia a importância dos conteúdos, mas priorizava uma demanda de Marina de estar com o outro e de estabelecer relações. Percebi que caberia a mim a criação de um projeto de inclusão para Marina, já que a escola pouco havia se preocupado até então com o encaminhamento daquela aluna e com a maneira como ela se encaixava em sala de aula.

Havia muita dificuldade de comunicação com a aluna nas primeiras semanas. Eu tentava "alcançá-la", mas parecia que nunca chegaria a ela. Fazia diversas perguntas para conhecê-la 
melhor: "O que você gosta de fazer?", "Qual sua matéria favorita?", “O que faz durante o fim de semana?", "Qual seu prato predileto?". As respostas eram curtas, e davam a impressão de que Marina havia sido programada para dá-las de forma quase robótica: "Acho que sim", "Acho que não", "Também", "Todas". Além disso, Marina falava em um tom de voz baixo e com dicção pouco articulada. Eu não sabia qual caminho seguir.

Os dias passavam e eu me sentia quase sufocada. O trabalho se resumia a passar tarefas, anotar as lições da lousa e avaliar quais exercícios seriam adequados. Mas isso não parecia fazer sentido, especialmente porque Marina parecia cada vez mais uma máquina programada, apresentando um discurso completamente descolado de qualquer afetividade.

Percebia que ela gostava muito de escrever - nas aulas de redação sempre fazia textos de várias páginas. Foi a partir deste momento e desta minha percepção que começamos a trocar cartas; achei que, dessa forma, conseguiríamos nos comunicar melhor.

Escrevi uma carta me apresentando, dizendo meu nome, explicando o que eu fazia e o que eu gostava de fazer e terminei dizendo: "Acho que podemos nos conhecer melhor por cartas, já que você gosta de escrever. Me conte um pouco de você. Beijos". Sua resposta foi um pouco menos programada do que sua fala. A partir desse primeiro diálogo escrito não paramos mais de nos corresponder, até o final do acompanhamento.

No início do nosso processo de troca de cartas, ela sempre repetia o discurso: contava como imaginava sua vida no futuro e terminava de forma incompreensível. Aos poucos, as cartas que trocávamos foram se transformando em folhas de diálogo.

Durante os intervalos, Marina descia até o pátio para tomar seu lanche. Eu fui orientada a descer com ela e acompanhá-la nesse período, de forma a evitar que subisse de volta para a sala de aula rapidamente. Isso era chamado de socialização pela orientação da escola. Ela de fato lanchava naquele espaço, pois assim havia sido "solicitado"; de resto, não havia convívio com outros alunos. Eu sempre perguntava-lhe se poderia me sentar ao lado dela, mas, mesmo com a evolução do discurso nas cartas, ela parecia não querer minha companhia na hora do lanche. Eu respeitava e não me sentava. Um dia a questionei de forma direta e perguntei se não seria mais agradável tomar lanche com uma companhia; Marina respondeu que ela se fazia companhia, que não precisava de ninguém e que era importante ser autônoma. "O que é ser autônoma?", repliquei. "Fazer tudo sozinha." Esse discurso sobre autonomia nos acompanhou durante todo o ano, afinal Marina estava sendo programada para viver uma grande solidão - na verdade, estava vivendo esse estado há muito tempo. O maior equívoco, nesse discurso, era não perceber que só se pode ser autônomo na presença de outro; no caso de Marina não havia a possibilidade de reconhecimento desse outro. 
Aos poucos fui me aproximando de Marina. Nossa troca de cartas se tornava mais frequente e, por mais que ela não tomasse a iniciativa de enviar a primeira mensagem, eu percebia que ela adorava recebê-las e respondê-las. Em determinado período ela começou a fazer perguntas sobre minha vida. Percebi, com isso, que havíamos firmado nossa relação: pela primeira vez li algo que parecia genuíno dela, frases que não eram montadas; aparecia, enfim, uma espontaneidade em seu discurso.

Apesar de considerar mais importante desenvolver aspectos sociais com Marina, eu não desconsiderei o viés pedagógico. A maioria dos professores, principalmente no início do acompanhamento, não preparava materiais adaptados para a aluna. Havia pouco sentido, então, em Marina ficar sentada na sala de aula sem ter acesso a conteúdos especiais para sua compreensão. Quando havia questões em folhas de exercício que Marina não entendia, ela travava e dava respostas desconexas, como "hoje é segunda e amanhã terça". Mesmo sem experiência pedagógica profissional, resolvi me arriscar e passei a propor, de forma independente, exercícios que faziam parte de seu cotidiano ao mesmo tempo em que se conectavam com o conteúdo das disciplinas.

Aos poucos passei a perceber que as demandas e o "projeto de inclusão" da escola seguiam o desejo dos pais, de que Marina passasse pelos passos "normais" da vida, não se preocupando com a singularidade da filha. Se os pais de Marina não se preocupassem com o conteúdo disciplinar diferenciado, a escola também não se preocuparia.

Durante nossa convivência fui compreendendo melhor a relação entre Marina e os pais. Ela me contava que tinha autonomia e que era estimulada/forçada a fazer tudo sozinha - "Autonomia é muito importante para mim", ela dizia. Na escola, não gostava de se aproximar de seus colegas, dizia que não precisava deles e que estar só era seu objetivo. Em casa, Marina jantava sozinha, o que parecia um exercício para sua independência: seus pais e irmã jantavam juntos, e ela esquentava sua refeição mais tarde e comia em seu quarto. Quando eu perguntava sobre seu fim de semana, a resposta era sempre a mesma: "Dei volta de carro com meu pai". "Mas, Marina, você foi aonde com seu pai?", eu retrucava. "Fui dar volta." "Vocês saíram do carro?", eu insistia. "Não." Marina só saía do carro para frequentar encontros de um grupo de jovens também portadores de síndrome de Down.

Como acreditar que Marina era realmente autônoma se quase não saía de casa? Será que jantar sozinha é ser independente? Que Marina autossuficiente esses pais enxergavam?

Como disse anteriormente, meu cargo na escola era de auxiliar de sala. Entretanto, sempre atuei mais como acompanhante terapêutica, e nunca deixei de lado meu olhar atento de psicóloga. Assim, pude perceber que o mais importante nesse atendimento seria a construção de uma verdadeira relação com Marina.

Aos poucos estabelecemos um relacionamento em que Marina confiava em mim e sentia-se à vontade para me mandar cartas e fazer perguntas; por vezes, 
permitia-se até deixar de lado exercícios escolares para poder trocar experiências. Houve um episódio em que eu, preocupada com o conteúdo das aulas, passei uma série de exercícios e Marina me escreveu o seguinte: "Não se preocupe Bruna, a ficha já está feita, agora vamos conversar sobre o feriado, conte um pouco de sua vida, fez algo especial?". Nunca havia recebido uma carta como essa de Marina; foi nesse momento que percebi nossa nova relação.

Marina passou a demonstrar mais afetividade pelos outros, vontade de conversar e de participar de situações em grupo. Quando ela começava a falar, todos os meninos se juntavam em volta dela e Marina não parava mais; gostava da atenção, de estar junto. Os professores, que no início diziam "Ela não dá trabalho", e que pouco interagiam com ela, vinham até mim impressionados com a mudança de postura de Marina: "Ela está participativa!". Parecia que Marina surgia aos olhos dos outros.

Quais as possibilidades, portanto, da inclusão diante do modelo de instituição escolar e qual a influência que ela exerce no projeto de singularização dos alunos?

\section{Inclusão escolar: um exercício de cidadania}

Como falar de inclusão sem tomar por seu aspecto negativo? Em geral fala-se mais da exclusão do que da inclusão, e essa vivência parece emergir de forma muito mais marcante em nossa sociedade. A questão inclusão/exclusão é amplamente discutida, tomada nos âmbitos social, econômico e político. $\mathrm{O}$ objetivo deste artigo é o de enquadrar uma visão sobre o conceito de inclusão para, assim, conseguir de forma mais consistente enxergá-lo no contexto do ambiente escolar.

Ao falar da inclusão, falamos de um conflito histórico e pertencente a certo funcionamento social, determinado pela exclusão social; o sistema em que vivemos é excludente em sua raiz. Dessa forma, falar em inclusão é perceber as práticas exclusivas constitutivas de nossa sociedade, uma sociedade de desiguais. (Machado, Almeida, Saraiva, 2009, p. 21)

De um lado há aqueles que excluem, e do outro há os excluídos; há, enfim, uma dinâmica autoritária entre essas duas posições: a primeira escolhe quem poderá ou não fazer parte dos incluídos, reflexo das relações sociais que acompanhamos na História.

Segundo Sposati (1998), a exclusão social denuncia a ruptura da noção de responsabilidade social e pública, e a quebra da universalidade da cidadania. Em conformidade com essa visão da autora, neste trabalho a exclusão será considerada uma negação da cidadania, ou seja, de que são negados a certos membros da sociedade seus direitos civis. 
Os direitos civis referem-se à liberdade individual, os direitos políticos dizem respeito à participação no exercício do poder político através da representação ou da participação e os direitos sociais compreendem o bem-estar do indivíduo, isto é, direitos à segurança, ao trabalho, ao lazer, à educação, à saúde, entre outros. (Brumer, Pavei, Mocelin, 2004, p. 300)

Poderíamos cair no erro de concluir, então, que para haver inclusão seria necessário encarar todos os cidadãos como iguais, afinal, considerar um outro como diferente poderia causar sua exclusão. Contudo, este trabalho defende a possibilidade da diferença e da singularidade, distanciando a conexão entre diferença e exclusão.

Segundo Kupfer (2005):

O ponto de partida para articular diferença com igualdade pode ser outro: é possível afirmar que a diferença não é um desvio da norma, mas surge dela, emerge a partir da lei. A diferença precisa da igualdade, tomada agora em sua acepção de norma geral para todos, para poder se engendrar. (p. 20)

Assim como a inclusão nasce da exclusão, a igualdade nasce da diferença. Seguindo o raciocínio da autora, citado acima, mas agora por um viés psicanalítico, a articulação da discussão passa a abranger outros temas, como o particular e o geral, o singular e o universal. Kupfer (2005) coloca que o sujeito nasce do Outro, ou seja, não se pode separar completamente o indivíduo da sociedade e da cultura. Quando o indivíduo se deita no divã, ele traz consigo, inevitavelmente, o Outro.

"Pode-se afirmar, a partir da psicanálise, que é da igualdade na lei simbólica, na estrutura geral, que pode surgir a diferença ou a singularidade” (p. 23). Ou seja, é preciso que consideremos todos como iguais para, dessa forma, percebermos as diferenças e tomá-las não como discriminativas, mas como constituintes da singularidade do sujeito.

Voltando à questão inicial, passa-se a enxergar a inclusão como direito à cidadania e, mais do que isso, como modo de trazer à margem as diferenças como elemento enriquecedor da sociedade, partindo do princípio de que são justamente as diferenças que constituem a singularidade dos indivíduos que a compõe. Assim, é relevante a visão de que todos têm os mesmos direitos e deveres perante a lei, afinal, como dito acima, é importante haver igualdade, desde que ela não negue as especificidades de cada indivíduo.

Percebe-se, assim, que o tema inclusão escolar possui certa dimensão que ultrapassa o plano da instituição escolar; trata-se de uma organização social e cultural, que é reproduzida dentro da educação. Ter acesso ao ensino significa poder reafirmar seu lugar de cidadão de direitos dentro de uma sociedade, ter acesso à cultura e trocas com outros colegas e com o universo que a escola traz consigo. Dessa forma, a inclusão escolar traz com ela a inclusão social. Quando os muros de uma escola são altos demais, a ponto de impedir o acesso a ela de certo grupo de crianças, isso reflete 
o fato de que nossa sociedade também está fechada para esse grupo. Segundo Charles Gardou (2011), no artigo Pensar a deficiência numa perspectiva inclusiva:

... a deficiência não resulta exclusivamente da deficiência ou da pessoa em si, mas, por um lado, da forma como os espaços de educação, de cultura, de trabalho e, de modo geral, a sociedade a considera e, por outro lado, as respostas que eles lhe dão. (p. 15)

\section{A educação e a emergência de um sujeito}

O livro Educação impossível, de Maud Mannoni (1977), nos inspira a refletir sobre o que venha a ser a inclusão escolar. A autora relata a experiência da Escola de Bonneuil, que possibilitou aos seus frequentadores um lugar diferente do que sempre lhes havia sido imposto, as instituições médico-pedagógicas. A Escola de Bonneuil se constitui como um lugar de vida, ou seja, um local que pretende a não reprodução dos já conhecidos modelos de tratamento e adequação, permitindo que os alunos possam expressar seus desejos.

Mannoni descreve uma trajetória que tem seu fim na exclusão de crianças do ambiente escolar:

Se a descoberta da criança constitui o grande acontecimento dos tempos modernos (provocando o aparecimento da instituição educacional), a da criança deficiente (e da instituição médico-educacional que a ela se consagra) constitui, como já vimos, o evento marcante da época contemporânea. (p. 156)

Esse caminho, segundo a autora, se deve por reproduzirmos nas instituições educacionais um modelo que separa completamente o aluno do professor, segundo o qual um detém todo o conhecimento, enquanto o outro não sabe nada, limitando o conteúdo escolar (Mannoni, 1977). Estabelece-se uma relação de poder, que acaba impedindo o aluno de aprender. O educador institui um ideal a ser atingido, ignorando o desejo do aluno. A consequência dessa relação é o sintoma, ocasionando as inadaptações (Mannoni, 1977), e o resultado desse sistema é o surgimento das escolas paralelas, as ditas "especiais".

Segundo Machado (2005), boa parte dos encaminhamentos feitos a clínicas-escola e postos de saúde envolve queixas escolares. São alunos mal-educados, indisciplinados ou que não conseguem aprender. A autora afirma que a demanda que se coloca como um problema individual, de determinado aluno, é equivocada. A queixa escolar nasce de um coletivo, de uma construção. Os professores carregam em seu discurso o modelo de como certo estudante deveria ser, formando a dificuldade nele, sem perceber que são os próprios educadores que estabeleceram essa meta. 
A partir desse modus operandi descrito pelas duas autoras, é possível enxergar claramente como a exclusão/inclusão escolar é arquitetada no cotidiano. Esse modelo constrói o conceito de criança deficiente ou "especial", aquela que deve ser cuidada por médicos, e não pela instituição escolar.

O discurso médico psiquiatra, segundo Mannoni (1977), atualmente liga-se a uma ideologia de resultados e adaptação em uma sociedade que prioriza a produção: "Esse saber é posto ao serviço de ideias de rendimento e eficácia - e isso produz efeitos sobre os programas escolares ou os tipos de instituições educacionais e assistências criadas" (p. 152). Dessa forma, aquele que não se encaixa no modelo torna-se "enfermo", com necessidade de tratamento.

O trabalho com Marina seguiu a ideia de inclusão, apresentada anteriormente, mas sempre feita a partir da relação com a aluna, e não somente de um conceito. Dizer somente o que é a inclusão nos impede de pensar o singular da experiência com o sujeito, portanto é preciso pensar em inclusões.

Apesar da influência da ideologia médica de sua época, Freud sabe estar à escuta de uma experiência e ouvir o dizer do paciente, a partir do que ele participa nesse dizer, porquanto se abstém de ocupar na relação assistente/assistido qualquer posição de autoridade. O paciente não constitui para ele (como era o caso de Itard) a tela em que se projeta um saber teórico. Isto é uma diferença essencial. (Mannoni, 1977, p. 162)

Mannoni descreve de forma muito clara o modo que Freud trabalhava e que se liga diretamente a como foi minha atuação durante o acompanhamento de Marina. As instituições escolares, em sua grande maioria, pautam-se pelas relações de autoridade, em que o professor é a figura do saber absoluto, que tem o dever de passar este saber aos alunos, que compõem essa "tela" vazia.

No mesmo caminho que Mannoni, Charles Gardou e Michel Develay, no artigo "O que as situações de deficiência e a educação inclusiva 'dizem' às Ciências da Educação", trazem, entre muitas questões, a forma como situações de deficiência acabam sendo tratadas dentro da instituição escolar. Logo adiantam que "a educação é a arma mais poderosa contra o desprezo e a segregação" (p. 32), especialmente em lugares em que há intolerância a um grupo de indivíduos, e que aqueles que discriminam negam a cidadania dos mais vulneráveis. Os autores compartilham ideias de autor do livro $O$ normal e o Patológico, aproximando-se do conceito de que a patologia se trata de um estado temporário, e não de algo estático, assim como a normalidade; ou seja, nós, como indivíduos, transitamos entre esses dois estados. O conceito do normal corresponde a uma norma, e esta "apresenta-se sempre como um modo de supressão gradual da diferença e da uniformização da diversidade: serve para tornar direito, dirigir, redirigir" (p. 39). É a partir do modelo normal que muitas escolas pautam seu programa pedagógico, tornando o anormal aquele que é detentor de todos os valores negativos. Segundo Canguilhem, deveria 
pensar-se a deficiência como diferença, como um modo de estar. Do contrário, se forem pensadas como anormalidades e a escola se deixar pautar por categorizações, ignora-se a possibilidade da plasticidade humana, de poder se transformar, e a singularidade presente em cada criança.

Ter um "insucesso" refere-se à expectativa do pedagogo em tentar encaixar um indivíduo a um modelo. Dessa forma, seria necessário dizer que a criança foi colocada em uma situação de insucesso. É preciso que o educador mude sua relação e postura, não somente perante os alunos, mas também perante todos os outros indivíduos; somente assim poderia haver a aceitação da diferença.

Educar é favorecer a emergência de uma alteridade não concedida ou consentida, às crianças diferentes pelo azar do nascimento ou pelos imprevistos do destino, mas uma alteridade reivindicada pelo educador, somente suscetível de existir diante de uma sociedade plural. (p. 42)

Os autores concluem dizendo que apenas se a pedagogia e os professores pensarem o impossível como possível, recusando determinismos e admitindo que o ser humano é plural, complexo e plástico, poderíamos alcançar não somente uma educação inclusiva, mas uma sociedade inclusiva também.

$\mathrm{O}$ trabalho com Marina foi feito dando prioridade à escuta e à experiência, em uma relação de construção, não de poder; o aprendizado era fruto da relação com outra pessoa. Assim foi possível o desenvolvimento de um projeto singular para a aluna, do qual ela participava ativamente, podendo interferir no próprio processo. Poder escutá-la em seu desejo, e não no desejo que o professor autoritário espera de seus alunos, permitiu que emergisse uma Marina menos mecânica, trazendo à tona sua espontaneidade e, consequentemente, a possibilidade de uma nova relação com os outros.

Nesse sentido, a atuação no trabalho com Marina assemelha-se à Educação Terapêutica descrita por Kupfer. Em seu artigo "O sujeito na psicanálise e na educação: bases para a educação terapêutica" (2010), a autora estabelece a diferença entre o conceito de sujeito presente no campo da educação e na psicanálise, para fundamentar a Educação Terapêutica.

A noção de sujeito que atualmente vemos na educação, e culturalmente também, é sinônimo de indivíduo, tomada como a possibilidade da liberdade. Esse conceito contradiz a origem da palavra. Segundo a autora, o termo sujeito vem do latim subjectum - aquele que está sujeitado, submetido. Kupfer (2010) faz uma perspectiva da noção de sujeito em Aristóteles e na filosofia moderna, e investiga seu sentido em Freud e Lacan, concluindo que:

Assim, para a psicanálise, o sujeito do inconsciente se constitui na e pela linguagem. Desta perspectiva, a linguagem não é instrumento de comunicação, mas a trama mesma que faz o sujeito. Tal formação aparece de modo evanescente, nos 
interstícios das palavras. No entre dois. Não há liberdade nesse surgimento, não há escolha. O sujeito não fala, mas é falado. (p. 270)

Para a psicanálise o sujeito também é “assujeitado”, não diz da liberdade e é só possível na relação com o Outro por intermédio da linguagem. O sujeito do inconsciente diz que sempre haverá algo que não poderemos saber, somos cindidos, estaremos sempre submetidos ao oculto, ao inconsciente. Essa divisão é obra do recalque que separa o Eu de seu Eu inconsciente, acobertando o que não queremos saber.

A Educação Terapêutica descrita pela autora tem como base essa noção de sujeito e compreende que

... a escola de nossos dias busca ser "inclusiva", supondo que bastará incluir ou pôr para dentro de seus muros uma ou outra criança diferente, quando se trata, ao contrário, de produzir profundas e estruturais mudanças, que permitam a introdução da noção de diferença em seu fundamento educativo. (p. 273)

Para alcançar essas mudanças estruturais, a autora propõe um trabalho que segue três eixos: "... a inclusão escolar, o tratamento institucional e o educacional propriamente dito. Nos três eixos, o objetivo é o surgimento do sujeito" (p. 275).

A própria denominação que se costumava dar a esses alunos já escancara a forma que a instituição escolar tradicionalmente costuma trabalhar:

O perigo das palavras novas que escondem aquilo que se repete criando uma ilusão de mudança. Vejamos: inicialmente falávamos de "crianças com distúrbios de aprendizagem", depois de "crianças especiais", depois de "portadores de necessidades educacionais especiais". Hoje escutamos falas do tipo "estou com duas crianças de inclusão" em minha sala. Essas crianças se tornaram "crianças de inclusão". Como manter a tensão que pode se perder na invisibilidade criada quando reduzimos as práticas educativas à permanência das crianças no interior das classes regulares? Como incluir, nessa discussão, aqueles que têm sido reiteradamente excluídos dos espaços de reflexão: pais, mães e alunos? (Machado, 2004, p. 6-7)

Machado (2004), ao evidenciar o perigo das palavras usadas no meio educacional, mostra que o trabalho de inclusão, como já discutido, não se trata somente de colocar um aluno dentro de uma sala de aula regular, mas de poder criar novos processos de pensar a diferença e a educação, por isso é preciso promover discussões entre os educadores. Somente eles poderão mudar os estigmas no coletivo de uma sala de aula. Enquanto os professores não se implicarem com essa reflexão, a exclusão estará presente, afinal, sempre existirão os "alunos de inclusão" ou os "desajustados".

A autora coloca que "cada criança que desafia a estrutura de uma certa escola exige um projeto singular" (Machado, 2004, p. 10), mas esse projeto só é possível se forem pensados os processos de subjetivação de cada um. Segundo Machado, as escolas funcionam pelo atacado, no coletivo; assim, ao aceitar uma criança como Marina, seria necessária uma reflexão. Quando isso não acontece, a aluna 
permanece excluída, e a possibilidade de se alcançar o objetivo de uma educação terapêutica (o surgimento do sujeito) é afastado.

\section{Considerações finais}

Compreender o trajeto de um projeto singular para uma aluna portadora de sindrome de Down permite visualizar uma possibilidade de transformação, em que escolas regulares poderiam se implicar na educação de todos, mesmo que cada um apresente sua especificidade.

Somente por meio de um olhar e uma escuta atentos, e a percepção de que a educação se faz por meios muito maiores do que uma lousa e um giz, é que foi possível desenvolver um trabalho pelo qual Marina pudesse surgir como sujeito. Impossível negar que o afeto faça parte da educação; a relação professor-aluno, quando se apresenta de forma autoritária, separa o aluno do conhecimento. Poder construir um processo de aprendizado junto ao aluno é conseguir sair da posição de saber absoluto, tornando tangível a educação para todos.

\section{Referências}

Brumer, A.; Pavei, K. \& Mocelin, G. (2004). Saindo da "escuridão": perspectivas da inclusão social, econômica, cultural e política dos portadores de deficiência visual em Porto Alegre. Revista Sociologias, Porto Alegre, 6(11), 300-327.

Gardou, C. \& Develay, M. (2005). O que as situações de deficiência e a educação inclusiva “dizem” às Ciências da Educação. Rev. Lusófona de Educação, Lisboa, 6. Recuperado em 12 mar. 2013 de <http://www.scielo.gpeari.mctes.pt/scielo.php?script=sci_arttext \&pid $=\mathrm{S} 164572502005000200003 \& \operatorname{lng}=\mathrm{pt} \& \mathrm{nrm}=\mathrm{iso}>$.

Gardou, C. (2011). Pensar a deficiência numa perspetiva inclusiva. Rev. Lusófona de Educação, Lisboa, n. 19, 2011. Recuperado em 25 mar. 2013 de: <http://www.scielo.gpeari.mctes. pt/scielo.php?script=sci_arttext\&pid=S164572502011000300002\&lng=pt\&nrm=iso $>$.

Kupfer, M. C. M. (2005). Travessias Inclusão Escolar: a experiência do grupo ponte pré-escola terapêtica Lugar de Vida. São Paulo: Casa do Psicólogo.

Kupfer, M. C. M. (2010). O sujeito na psicanálise e na educação: bases para a educação terapêutica. Revista Educação e Realidade, 35(1), 265-282.

Machado, A. M. (2004). Educação Inclusiva: de quem e de quais práticas estamos falando?. 27 Reunião Anual da ANPEd, Minas Gerais.

Machado, A. M. (2005). Articulação da saúde com a educação nos desafios da educação inclusiva. In Educação Inclusiva: direitos humanos na escola (pp. 71-83). São Paulo: Casa do Psicólogo. 
Machado, A. M.; Almeida, I. \& Saraiva, L. F. O. (2009). Rupturas necessárias para uma prática Inclusiva. In Educação Inclusiva: experiências profissionais em psicologia (pp. 21-36). Brasília: Conselho Federal de Psicologia.

Mannoni, M. et al. (1977). Educação impossível. (Álvaro Cabral, trad.). Rio de Janeiro: Francisco Alves.

Mendes, E. G. (2006, set.dez.). A radicalização do debate sobre a inclusão escolar no Brasil. Revista Brasileira de Educação, São Carlos, 11(33), 387-559.

Sposati, A. (2004). Exclusão social abaixo da linha do Equador. Seminário Exclusão Social, PUC-SP, 23/04/1998.

\section{Resumos}

(Possibilities and challenges for inclusion in schools)

Here we discuss the therapentic relationship developed with a student with Down's syndrome, and her progress and relationships at the school she attends. We discuss the possibilities of creating an individual project, and the role education plays in establishing a desiring subject.

Key words: School inclusion, psychoanalysis, therapeutic relationship and education

(Possibilités et défis de l'inclusion scolaire)

Le cas en question porte sur l'accompagnement thérapeutique d'une élève atteinte du syndrome de down, le processus de son suivi et de celui de son lycée. Nous discutons la possibilité de créer un projet singulier et le rôle que l'éducation joue dans la formation d'un sujet désirant.

Mots clés: Inclusion scolaire, psychanalyse, accompagnement thérapeutique et éducation

(Posibilidades y desafíos en la inclusión escolar)

Se presenta un caso de acompañamiento terapéutico realizado con una estudiante portadora de la Síndrome de Down, siguiéndola en su trayectoria de vida en su escuela. Se discute la posibilidad de desarrollar un proyecto singular así como el papel de la educación para el surgimiento de un sujeto "deseoso".

Palabras clave: Inclusión escolar, psicoanálisis, acompañamiento terapéutico y educación

(Möglichkeiten und Herausforderungen bei der Integration in der Schule)

Hier wird die therapeutische Begleitung einer Schülerin mit Downsyndrom dargestellt, wie die Entwicklung mit ihr und mit der Schule verläuft. Es wird diskutiert, 
wie ein einmaliges Projekt entwickelt werden kann und auf welchem Stand sich das Bildungswesen befindet, um zur Entstehung einer Person mit Willen beizutragen.

Schlüsselwörter: Integration in der Schule, Psychoanalyse, therapeutische Begleitung und Erziehung

Citação/Citation: Kibrit, B. (2013, dezembro). Possibilidades e desafios na inclusão escolar. Revista Latinoamericana de Psicopatologia Fundamental, 16(4), 683-695.

Editor do artigo/Editor: Profa. Dra. Ana Cecilia Magtaz

Recebido/Received: 15.9.2013/ 9.15.2013 Aceito/Accepted: 26.11.2013/11.26.2013

Copyright: (C) 2009 Associação Universitária de Pesquisa em Psicopatologia Fundamental/ University Association for Research in Fundamental Psychopathology. Este é um artigo de livre acesso, que permite uso irrestrito, distribuição e reprodução em qualquer meio, desde que o autor e a fonte sejam citados / This is an open-access article, which permits unrestricted use, distribution, and reproduction in any medium, provided the original author and source are credited.

Financiamento/Funding: A autora declara não ter sido financiada ou apoiada / The author has no support or funding to report.

Conflito de interesses/Conflict of interest: A autora declara que não há conflito de interesses / The author declares that has no conflict of interest.

\section{Bruna Kibrit}

Psicóloga formada pela Pontifícia Universidade Católica de São Paulo - PUC-SP (São Paulo, SP, Br); especialista em Psicopatologia e Saúde Pública pela Faculdade de Saúde Pública da Universidade de São Paulo - USP (São Paulo, SP, Br); Atua como acompanhante terapêutica junto ao Grupo Laço - Projetos de Inclusão Escolar (São Paulo, SP, Br).

Rua Igarapava, 76 - Itaim-Bibi

04531-100 São Paulo, SP, Br

e-mail: brunakibrit@gmail.com 